\title{
THỰC HÀNH BẢO QUẢN VÀ CHẾ BIẾN THỰC PHẨM CỦA NGỮ̀I DÂN TẠI HUYỆN ĐÔNG ANH, THÀNH PHỐ HÀ NỘI NĂM 2018
}

Đặng Quang Tân ${ }^{1}$, Nguyễn Thị Hải Yến ${ }^{2}$, Nguyễn Quang Dũng ${ }^{1}$, Lê Thị Hưong ${ }^{1}$, Phan Thị Kim ${ }^{3}$

${ }^{1}$ Đại học Y Hà Nội

${ }^{2}$ Trung tâm kiểm soát bệnh tật Hà Nội

${ }^{3}$ Viện thực phẩm và dinh dữong gia đình

(Ngày đến tòa soạn: 13/9/2019; Ngày sủa bài sau phản biện: 20/9/2019;

Ngày chấp nhận đăng: 1/10/2019)

\section{Tóm tắt}

Mục tiêu: Mô tả thực trạng thực hành bảo quản và chế biến thực phẩm của người dân tại huyện Đông Anh, thành phố Hà Nội năm 2018.

Phương pháp: Nghiên cứu mô tả cắt ngang trên 312 người dân được phỏng vấn theo bộ câu hỏi về thực trạng thực hành về bảo quản và chế biến thực phẩm.

Kết quả: Khoảng một nửa số người dân tham gia nghiên cứu có kiểm tra hạn sử dụng các nhóm thực phẩm thường xuyên. Về bảo quản thực phẩm trong tủ lạnh có $78,9 \%$ người dân bảo quản thịt trong ngăn phía trên của khoang mát; $90,1 \%$ người dân bảo quản rau trong ngăn phía dưới của khoảng mát; $82,9 \%$ người dân bảo quản thức ăn chín trong tủ lạnh. Có 78,9\% người dân có sử dụng thớt riêng cho thực phẩm sống chín. 55,1\% người dân sử dụng dầu thực vật; $32,3 \%$ người dân sử dụng cả dầu thực vật và mỡ động vật.

Kết luận: Tỷ lệ người dân có thực hành bảo quản và chế biến thực phẩm chưa cao. Cần tăng cường các chương trình tập huấn, truyền thông về các phương pháp bảo quản và chế biến thực phẩm.

Tù khóa: Bảo quản, chế biến thực phẩm, huyện Đông Anh, Hà Nội.

\section{1. ĐẠT VẤN ĐỀ}

An toàn thực phẩm hiện đang là một vấn đề nổi cộm và được sự quan tâm của toàn xã hội. Vấn đề thực phẩm sạch và an toàn hiện đang là mối quan tâm hàng đầu của người tiêu dùng, bởi an toàn thực phẩm không chỉ ảnh hưởng trực tiếp, thường xuyên đến sức khỏe người tiêu dùng mà còn liên quan chặt chẽ đến năng suất, hiệu quả phát triển kinh tế và an sinh xã hội [1]. Những bệnh truyền qua thực phẩm luôn là mối đe dọa lớn với sức khỏe toàn cầu [2]. Mỗi năm, ở các nước phát triển, hàng triệu người bị ngộ độc thực phẩm và tử vong do ăn phải thực phẩm không an toàn, một phần ba dân số bị ảnh hưởng bởi bệnh do thực phẩm gây ra, vấn đề này còn nghiêm trọng hơn ở các nước đang phát triển [3]. Đặc biệt, tại các nước đang phát triển tình hình an toàn thực phẩm và các bệnh truyền qua thực phẩm nghiêm trọng hơn do hạn chế chung về điều kiện đảm bảo an toàn vệ sinh thực phẩm [4],[5].

Việc đảm bảo an toàn thực phẩm bao gồm đảm bảo an toàn trong sản xuất, chế biến và tiêu thụ thực phẩm. Trong con đường của thực phẩm "từ trang trại đến bàn ăn”, khi vi phạm quy tắc an toàn nào cũng sẽ dẫn đến hậu quả là các bệnh lý ở người tiêu dùng. Do đó, người dân cần được biết về cách bảo quản và chế biến thực phẩm an toàn.

\footnotetext{
${ }^{1}$ Điện thoại:0349696042Ｅmail:quangtanhmu@gmail.com
} 
Bảo quản thực phẩm là sử dụng các biện pháp ngăn chặn sự phát triển của vi sinh vật và làm chậm quá trình tự phân hủy trong thực phẩm, nhằm mục đích giữ cho thực phẩm có thể sử dụng được trong thời gian dài mà không bị biến chất hư hỏng. Tuy nhiên, hiện nay số liệu về hiểu biết và thực hành của người dân tại Hà Nội về vấn đề bảo quản và chế biến thực phẩm còn rất hạn chế, đặc biệt là người dân tại các huyện ngoại thành. Chính vì vậy chúng tôi tiến hành nghiên cứu này.

Mục tiêu nghiên cứu: Mô tả thực trạng thực hành bảo quản và chế biến thực phẩm của người dân tại huyện Đông Anh, thành phố Hà Nội năm 2018.

\section{2. ĐỐI TƯợNG VÀ PHƯỚNG PHÁP}

\subsection{Thời gian và địa điểm}

Từ tháng 11 năm 2018 đến tháng 4 năm 2019, tại xã Cổ Loa, huyện Đông Anh, thành phố Hà Nội.

2.2. Đối tượng nghiên cứu: Người dân từ 18 đến 64 tuổi thuộc địa bàn xã Cổ Loa, huyện Đông Anh, thành phố Hà Nội.

2.3. Thiết kế nghiên cứu: Mô tả cắt ngang

\subsection{Cõ̃ mẫu và chọn mẫu:}

Cỡ mẫu: được ước tính dựa vào công thức tính cỡ mẫu cho một tỷ lệ [6]:

$$
n=Z_{1-\alpha / 2}^{2} \frac{p(1-p)}{d^{2}}
$$

Trong đó:

- n: số học sinh cần chọn vào nghiên cứu;

- Độ tin cậy 95\%: Z1- $\alpha / 2=1,96$, khoảng sai lệch mong muốn $\mathrm{d}=0,05$;

- p: tỷ lệ người dân có thực hành về kiểm tra hạn sử dụng của thực phẩm thường xuyên.

Uớc tính có khoảng $75 \%$ người dân có thực hành về kiểm tra hạn sử dụng của thực phẩm thường xuyên.

Cỡ mẫu tính được là: $\mathrm{n}=288$ người.

Để hạn chế các ảnh hưởng do sai số, đối tượng từ chối, hoặc số học sinh được chọn nghỉ học, chúng tôi đã tăng số lượng đối tượng thêm 5\%. Cỡ mẫu nghiên cứu tính được là 303 học sinh.

Cách chọn mẫu:

Chọn ngẫu nhiên một xã tại huyện Đông Anh vào nghiên cứu, lập danh sách tất cả người dân từ 18 đến 64 tuổi tại xã sau đó chọn ngẫu nhiên đơn người dân từ danh sách cho đến khi đủ số lượng.

Thực tế cỡ mẫu điều tra được là 312 .

\subsection{Phương pháp thu thập thông tin}

Phỏng vấn đối tượng thông qua bộ câu hỏi về thực hành bảo quản, chế biến thực phẩmđược thiết kế sẵn, bộ câu hỏi đã được thử nghiệm trước khi tiến hành nghiên cứu.

\subsection{Phân tích thống kê}

Số liệu được làm sạch, mã hóa và nhập bằng phần mềm Epidata 3.1, sau đó được xử lý bằng phần mềm Stata 13, Excel 13.

\section{7. Đạo đức trong nghiên cứu}

Đối tượng nghiên cứu được giải thích rõ ràng về mục đích, ý nghĩa của nghiên cứu và tự nguyện tham gia nghiên cứu. Các thông tin thu thập được chỉ phục vụ cho mục đích nghiên cứu, không sử dụng cho mục đích khác và hoàn toàn được giữ bí mật. Nghiên cứu đã được thông qua Hội đồng đạo đức Viện đào tạo Y học dự phòng và Y tế công cộng, trường Đại học Y Hà Nội. 


\section{KẾT QUẢ}

\section{1. Đặc điểm đối tượng nghiên cứu}

Bảng 1. Thông tin chung của đối tượng nghiên cưu $(n=312)$

\begin{tabular}{llcc}
\hline \hline & $\mathbf{n}$ & \% \\
\hline Tuổi (năm) & & 72 & 23,1 \\
& $18-24$ & 98 & 31,4 \\
& $25-44$ & 142 & 45,5 \\
\hline $45-64$ & & \\
\hline Giới & 94 & 30,1 \\
& Nam & 218 & 69,9 \\
\hline Nữ & & \\
\hline Trình độ học vấn & 2 & 0,6 \\
Mù chữ & 26 & 8,3 \\
Tiểu học & 111 & 35,6 \\
Trung học cơ sở & 160 & 51,3 \\
Trung học phổ thông & 12 & 3,9 \\
Đại học & 1 & 0,3 \\
Sau đại học & & \\
Độc thân & 14 & 4,5 \\
Kết hôn & 295 & 94,6 \\
Li dị & 3 & 0,9 \\
\hline Tình trạng hôn nhân & &
\end{tabular}

Bảng 1 cho thấy, trong tổng 312 đối tượng nghiên cứu, nữ giới chiếm phần đông với $69,9 \%$. Về độ tuổi có $45,5 \%$ độ tuổi từ 45 đến $64 ; 31,4 \%$ từ 25 đến 44 tuổi và $23,1 \%$ từ 18 đến 24 tuổi. Về trình độ học vấn có $35,6 \%$ tốt nghiệp trung học cơ sở; 51,3\% tốt nghiệp trung học phổ thông và chỉ có $3,9 \%$ có trình độ đại học. Về tình trạng hôn nhân, đa phần đối tượng tham gia nghiên cứu đã kết hôn với 94,6\%.

\subsection{Thực trạng thực hành bảo quản và chế biến thực phẩm}

Bảng 2. Thực hành kiểm tra hạn sủ dụng của thực phẩm $(n=312)$

\begin{tabular}{ccc}
\hline & $\boldsymbol{n}$ & $\boldsymbol{\%}$ \\
\hline Thực phẩm bao gói sã̃n & 172 & 55,1 \\
Thường xuyên & 53 & 17,0 \\
Thỉnh thoảng & 25 & 8,0 \\
Hiếm khi & 62 & 19,9 \\
Không bao giờ & & \\
Thực phẩm đóng hộp & 175 & 56,1 \\
Thường xuyên & 45 & 14,4 \\
Thỉnh thoảng & 25 & 8,0 \\
Hiếm khi & 67 & 21,5 \\
Không bao giờ & & \\
\hline
\end{tabular}




\begin{tabular}{|c|c|c|}
\hline & $n$ & $\%$ \\
\hline \multicolumn{3}{|l|}{ Đồ khô (đậu, đỗ...) } \\
\hline Thường xuyên & 147 & 47,1 \\
\hline Thỉnh thoảng & 66 & 21,2 \\
\hline Hiếm khi & 21 & 6,7 \\
\hline Không bao giờ & 78 & 25,0 \\
\hline \multicolumn{3}{|l|}{ Thưc phẩm đông lạnh } \\
\hline Thường xuyên & 155 & 49,7 \\
\hline Thỉnh thoảng & 58 & 18,6 \\
\hline Hiếm khi & 24 & 7,7 \\
\hline Không bao giờ & 75 & 24,0 \\
\hline \multirow{2}{*}{\multicolumn{3}{|c|}{$\begin{array}{l}\text { Bảng } 2 \text { cho thấy, về việc kiểm tra hạn sử dụng của các nhóm thực phẩm, khoảng một nửa số } \\
\text { người dân tham gia nghiên cứu có kiểm tra thường xuyên. Trong đó nhóm thực phẩm bao gói sẵn } \\
\text { và nhóm thực phẩm đóng hộp lần lượt với } 55,1 \% \text { và } 56,1 \% \text {, nhóm đồ khô và nhóm thực phẩm đông } \\
\text { lạnh lần lượt với } 47,1 \% \text { và } 49,7 \% \text {. Ngoài ra tỷ lệ người dân không bao giờ kiểm tra hạn sử dụng của } \\
\text { các nhóm bao gói sẵn, thực phẩm đóng hộp, đồ khô và thực phẩm đông lạnh lần lượt với } 19,9 \% \text {; } \\
21,5 \% ; 25 \% ; 24 \% \text {. }\end{array}$}} \\
\hline & & Bảng 3.Thực hành bảo quản thục phẩm bằng tủ lạnh $(n=312)$ \\
\hline & $\mathbf{n}$ & $\%$ \\
\hline \multicolumn{3}{|c|}{ Bảo quản thịt trong khoang mát tủ lạnh } \\
\hline Ngăn phía trên & 240 & 78,9 \\
\hline Ngăn phía dưới & 64 & 21,1 \\
\hline \multicolumn{3}{|c|}{ Bảo quản rau trong khoang mát tủ lạnh } \\
\hline Ngăn phía trên & 30 & 9,9 \\
\hline Ngăn phía dưới & 274 & 90,1 \\
\hline \multicolumn{3}{|l|}{ Bảo quản thục phẩm chín } \\
\hline Trong tủ lạnh & 252 & 82,9 \\
\hline $\begin{array}{l}\text { Bên ngoài tủ lạnh } \\
\text { (để hở) }\end{array}$ & 15 & 4,9 \\
\hline $\begin{array}{l}\text { Bên ngoài tủ lạnh } \\
\text { (trong hộp kín) }\end{array}$ & 37 & 12,2 \\
\hline
\end{tabular}

Kết quả bảng 3 cho thấy, trong 312 người dân tham gia nghiên cứu khi được hỏi thì cho thấy có 304 người trả lời là gia đình có tủ lạnh. Bảng 3 cho thấy có $78,9 \%$ người dân bảo quản thịt trong ngăn phía trên của khoang mát; $90,1 \%$ người dân bảo quản rau trong ngăn phía dưới của khoảng mát tủ lạnh. Về bảo quản thực phẩm chín thì trong số 304 người dân có tủ lạnh thì có $82,0 \%$ người dân bảo quản thức ăn chín trong tủ lạnh, 12,2\% người dân không bảo quản trong tủ lạnh mà bảo quản bằng hộp kín để bên ngoài tủ lạnh, có 4,9 người dân không bảo quản trong tủ lạnh mà để hở bên ngoài.

Hình 1. Tỷ lệ người dân sư dụng thớt riêng cho thực phẩm sống chín $(n=312)$

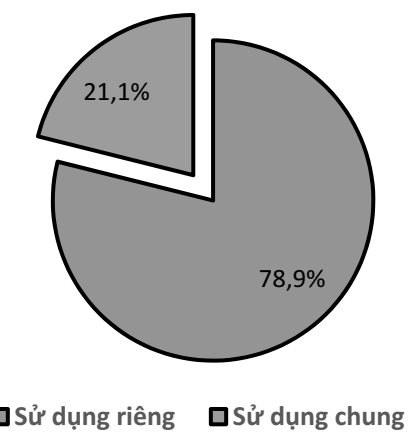


Hình 1 cho thấy, trong 312 người dân tham gia nghiên cứu có 78,9\% người có sử dụng thớt riêng cho thực phẩm sống chín.

Bảng 4. Thực hành sử dụng thớt trong quá trình chế biến thực phẩm $(n=312)$

$\mathbf{n}$

$\%$

Nếu không dùng riêng thớt cho thực phẩm sống chín,

Rưa thớt bằng xà phòng khi chuyển thực phẩm sống-

chin

Có

Không

Nếu không dùng riêng thớt cho thực phẩm sống chin,

Rưa tay bằng xà phòng khi chuyển thực phẩm sống-

chin

Có

45

68,2

Không
51

77,3

15

\begin{tabular}{lll} 
Có & 45 & 68,2 \\
Không & 21 & 31,8 \\
\hline
\end{tabular}

Bảng 4 cho thấy, trong số những người không sử dụng thớt riêng cho thực phẩm sống chín thì có $77,3 \%$ người dân có rửa thớt bằng xà phòng khi chuyển sử dụng thớt cho thực phẩm sống chín; có $68,2 \%$ người dân có rửa tay bằng xà phòng khi chuyển sử dụng thớt cho thực phẩm sống chín.

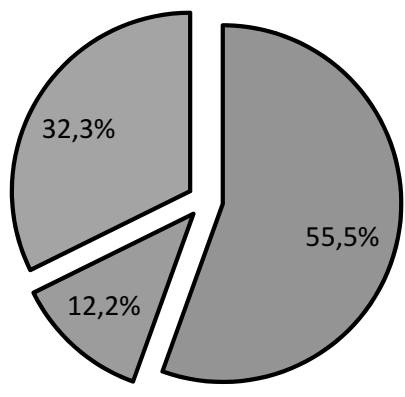

口Dầu thực vật $\quad$ Mỡ động vật $\quad$ Cả hai

Hinh 2. Tỷ lệ người dân sử dụng dầu mõ trong chế biến thực phẩm (n=312)

Hình 2 cho thấy, trong 312 đối tượng tham gia nghiên cứu có $55,5 \%$ người sử dụng dầu thực vật; $12,2 \%$ người sử dụng mỡ động vật và có $32,3 \%$ người sử dụng cả 2 loại trên trong chế biến thực phẩm.

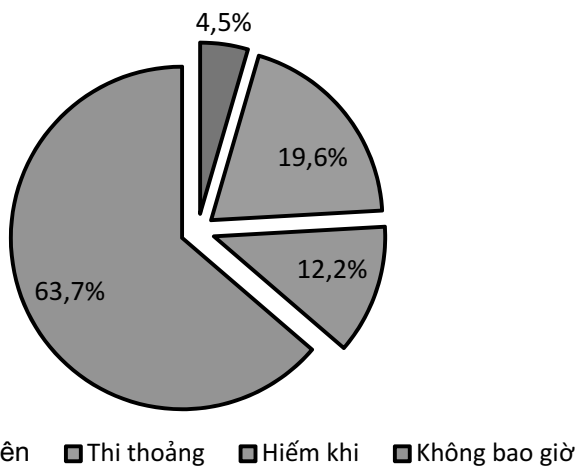

Hinh 3. Tỷ lệ nguời dân sử dụng lại dầu mõ̃ nhiều là̀n trong chế biến thực phẩm $(n=312)$ 
Hình 3 cho thấy, có $63,7 \%$ người dân tham gia nghiêm cứu không bao giờ sử dụng dầu mỡ chiên lại nhiều lần, ngoài ra lần lượt có $4,5 \% ; 19,6 \%$ và $12,2 \%$ người thường xuyên; thi thoảng và hiếm khi sử dụng dầu mỡ chiên lại nhiều lần.

\section{BÀN LUẬN}

Nghiên cứu trên tổng 312 người dân từ 18 đến 64 tuổi tại huyện Đông Anh cho thấy tỷ lệ người dân có kiểm tra hạn sử dụng của các nhóm thực phẩm khoảng $50 \%$. Kết quả này thấp hơn khá nhiều so với kết quả của Nguyễn Thùy Dương (2015) khi nghiên cứu về kiến thức, thực hành của người chế biến thực phẩm tại bếp ăn tập thể các trường tiểu học [7]. Kết quả có thể được giải thích do nghiên cứu của Nguyễn Thùy Dương trên người chế biến thực phẩm tại các bếp ăn tập thể có thể họ được học qua các lớp tập huấn nhiều hơn so với những người dân trong nghiên cứu của chúng tôi.

Kết quả cũng chỉ ra rằng có $82,9 \%$ người dân có bảo quản thực phẩm chín trong tủ lạnh. Kết quả này mặc dù tương đối cao tuy nhiên lại thấp hơn so với một số nghiên cứu trước đây của Đặng Quang Tân năm 2018 ở một số trường tiểu học tại Hà Nội với 98,8\% [8] và nghiên cứu của Ngô Oanh Oanh trên các trường mầm non của huyện Lâm Thao, Phú Thọ với 94,7\% [9]. Điều này cũng có thể được lý giải do nghiên cứu của Đặng Quang Tân cũng nghiên cứu tại các bếp ăn tập thể của các trường tiểu học, vì vậy có thể sẽ được tập huấn kỹ hơn đồng thời số suất tại các bếp ăn tập thể hằng ngày tương đối lớn, nhu cầu bảo quản thực phẩm trong tủ lạnh cấp thiết hơn. Trong khi đó nghiên cứu của chúng tôi thực hiện trên người dân của một xã ngoại thành Hà Nội, nên tỷ lệ này thấp hơn là cũng dễ hiểu. Kết quả cho thấy, tỷ lệ người dân bảo quản thực phẩm chín trong tủ lạnh là khá cao. Việc người dân bảo quản thực phẩm chín trong tủ lạnh có ưu điểm bảo quản thực phẩm được lâu, có thể dùng lại sau một thời gian, tuy nhiên nếu không bảo quản đúng cách và bảo quản trong thời gian dài sáu đó dùng lại có thể ảnh hưởng đến sức khỏe con người. Vì vậy việc tuyên truyền về bảo quản thực phẩm trong tủ lạnh cho nhân dân là việc làm vô cùng cần thiết và cần được cán bộ y tế triển khai tại địa phương.

Việc sử dụng thớt riêng biệt trong chế biến thực phẩm sống chín có vai trò vô cùng quan trọng trong đảm bảo an toàn thực phẩm cũng như trong quá trình chế biến thực phẩm. Kết quả chỉ ra rằng có $78,9 \%$ số người dân có sử dụng thớt riêng biệt cho chế biến thực phẩm sống và chín. Kết quả này thấp hơn so với nghiên cứu của Đặng Quang Tân về thực trạng An toàn vệ sinh thực phẩm tại bếp ăn tập thể của một số trường tiểu học thành phố Hà Nội năm 2018 với 95,2\% [10]. Trong số không sử dụng thớt riêng biệt vẫn còn $22,7 \%$ người dân không rửa thớt bằng xà phòng khi chuyển thớt sử dụng cho thực phẩm sống - chín; có 31,8\% người dân không rửa tay bằng xà phòng khi chuyển thớt sử dụng sống chín. Tỷ lệ này còn tương đối cao, phản ánh việc đảm bảo an toàn chế biến thực phẩm chưa được đẩy mạnh trong nhân dân.

\section{KẾT LUẬN}

Tỷ lệ người dân có kiểm tra hạn sử dụng các nhóm thực phẩm chưa cao, khoảng $50 \%$.Về bảo quản thực phẩm trong tủ lạnh có $78,9 \%$ người dân bảo quản thịt trong ngăn phía trên của khoang mát; $90,1 \%$ người dân bảo quản rau trong ngăn phía dưới của khoảng mát; $82,9 \%$ người dân bảo quản thức ăn chín trong tủ lạnh. Tỷ lệ người dân có sử dụng thớt riêng cho thực phẩm sống chín tương đối cao với $78,9 \% .55,1 \%$ người dân sử dụng dầu thực vật; $32,3 \%$ người dân sử dụng cả dầu thực vật và mỡ động vật.

\section{TÀI LIẸU THAM KHẢO}

1. Thu Hòa (2018), "Đẩy mạnh phát triển chuỗi cung ứng thực phẩm an toàn", Tạp chí Con số và Sự kiện, tổng cục thống kê số 7/2018 (532).

2. Nguyễn Hải, Phạm Thu (2012), "Gốc rễ, ngọn ngành của ngộ độc tập thể”, truy cập ngày 22/08/2012, tại trang thông tin sức khỏe và đời sống cơ quan ngôn luận Bộ Y tế, 
http://suckhoedoisong.vn/20120818085352474p61c67/goc-re-ngon-nganh-cua-ngo-doc-tapthe.htm.

3. Quốc hội khóa XII (2010), Luật An toàn thực phẩm, Nhà xuất bản Y học Hà Nội

4. E. Langiano, M. Ferrara, L. Lanni (2012), "Food safety at home: knowledge and practices of consumers", Z Gesundh Wiss, 20(1), p. 47 - 57.

5. R. Meysenburg, J. A. Albrecht, R. Litchfield (2014), "Food safety knowledge, practices and beliefs of primary food preparers in families with young children. A mixed methods study", Appetite, 73, p.121 - 131.

6. Lưu Ngọc Hoạt (2014), "Nghiên cứu khoa học y học”, Nhà xuất bản Y học, Trường Đại học Y Hà Nội.

7. Nguyễn Thùy Dương (2016), "Thực trạng an toàn thực phẩm và kiến thức, thực hành của người chế biến thực phẩm tại bếp ăn tập thể trường tiểu học khu vực nội thành Hà Nội năm 2015", Luận văn thạc sỹ Y học, Trường Đại học Y Hà Nội.

8. Đặng Quang Tân, Lê Thị Quỳnh Trang, Nguyễn Hoài Vũ (2019), "Kiến thức, thực hành của người chế biến thực phẩm tại bếp ăn tập thể của một số trường tiểu học thành phố Hà Nội năm 2018 và một số yếu tố liên quan", Tạp chi Y học thực hành, Số 4, tr 35 - 38.

9. Ngô Oanh Oanh (2016), "Thực trạng và quản lý an toàn vệ sinh thực phẩm tại bếp ăn tập thể các trường mầm non của huyện Lâm Thao, tỉnh Phú Thọ năm 2016”, Luận văn thạc sỹ y học, Trường Đại học Y Hà Nội.

10. Đặng Quang Tân (2019), "Thực trạng an toàn vệ sinh thực phẩm tại bếp ăn tập thể của một số trường tiểu học thành phố Hà Nội năm 2018”, Luận văn thạc sỹ y học, Trường Đại học Y Hà Nội.

\section{Summary}

FOOD STORAGE AND PROCESSING

IN DONG ANH DISTRICT, HANOI IN 2018

Dang Quang Tan', Nguyen Thi Hai Yen ${ }^{2}$, Nguyen Quang Dung', Le Thi Huong ${ }^{1}$, Phan Thi Kim ${ }^{3}$

${ }^{1}$ Hanoi Medical University

${ }^{2}$ Hanoi Center for Disease Control

${ }^{3}$ Institute of Food and Family Nutrition

The survey on food preservation and processing practices of local people was conducted in Dong Anh District, Hanoi in 2018. A cross-sectional descriptive study was carried out by interviewing 312 people. Results showed that, approximately $50 \%$ of the people participating in the study regularly checked the expired date of food. Regarding food preservation, $78.9 \%$ of people stored meats in the upper compartment of the cooler in refrigerators; $90.1 \%$ of people stored vegetables in the lower one; and $82.9 \%$ of people stored cooked food in refrigerators. In addition, $78.9 \%$ of people used separate cutting boards for cooked and raw foods; $55.1 \%$ of people used vegetable oil and $32.3 \%$ of people used both vegetable oil and animal fat. In conclusion, the rate of people having proper practice of food preservation and processing was not high. Therefore, training and communication programs on food preservation and processing methods should be strengthened.

Keywords: Food preservation and processing, Dong Anh district, Hanoi. 